\title{
Headspace solid-phase microextraction gas chromatography-mass spectrometry determination of volatile compounds in different varieties of African star apple fruit (Chrysophillum albidum).
}

\begin{abstract}
The volatile compounds in four selected African star apple fruit (Chrysophyllum albidum) varieties were isolated and identified using the headspace solid-phase microextraction (HSSPME) coupled with gas chromatography-mass spectrometry (GC-MS). A total of 59 compounds were identified. Application of the aroma extract dilution analysis (AEDA) to the aroma distillates from the fruits revealed 45 odour-active compounds in the flavour dilution (FD) factor range of 4-128. Among them, the highest odour activities (FD factors) were determined for methylhexanoate, acetophenone and ethyl dodecanoate. Moreover, aroma lipophilicity appears to reflect molecular conformation. Further analysis of the similarities and differences between the fruit varieties in terms of the key odourants by the application of PLS-DA and PLS-regression coefficient showed strong positive correlation between the very sweet/sweet varieties and 10 key odourants. The odourants included ethyl acetate, acetyl methyl carbinol, methylhexanoate, sabinene, p-cymene, methylbenzoate, ethylbenzoate, geraniol, cis- $\alpha$-bergomotene, acetophenone, and ethyl dodecanoate.
\end{abstract}

Keyword: African star apple fruit; HS-SPME; Volatiles; PLS-DA; PLS-regression coefficient. 